\title{
DSC STUDIES OF SOME BISMUTH-PHOSPHATE GLASSES
}

\author{
A.A. EL-ADAWY \\ Physics Department, Faculty of Science, Menuofia University, Egypt
}

(Received November 5, 1997; revised version May 25, 1998)

The differential scanning calorimetry measurements were made on a series of bismuth-iron-phosphate glasses over a temperature range around the glass transition temperature. The activation energy for structural relaxation, $\Delta H$, was determined and found to increase with the metal-to-phosphorus ratio. The differential scanning calorimetry data were analyzed using the Adam-Gibbs-Scherer model of the glass transition. This analysis suggests that these glasses undergo a transition from the strong to the fragile glass regime as the metal-to-phosphorus ratio is increased.

PACS numbers: $65.40 .+\mathrm{g}$

\section{Introduction}

The thermodynamics of the glass transition was first pointed out by Kauzmann [1] who reported that, without the glass transition, the entropy of the supercooled liquid would drop below that of the crystalline solid at a temperature $T_{2}$. Experimentally, however, the glass transition always occurred at a temperature $T_{\mathfrak{g}}$ above $T_{2}$, thus avoiding any thermodynamic catastrophe $[2,3]$.

The Adam-Gibbs model [4] proposed that the major driving force for the glass transition was the excess configurational entropy of the supercooled liquid in the temperature range between $T_{2}$ and the thermodynamic melting point. In the present work, the Adam-Gibbs model with an important modification proposed by Scherer [5] was used to analyze the differential scanning calorimetry (DSC) data of a series of bismuth-phosphate glasses.

The building blocks network in phosphate glasses are $\mathrm{PO}_{4}$ tetrahedra that are corner linked. For the bismuth and bismuth-iron-phosphate glasses investigated, the topology of the glass network varies significantly as the metal-to-phosphorus ratio is changed. The pure vitreous $\mathrm{P}_{2} \mathrm{O}_{5}$ is built up of an infinite network of $\mathrm{PO}_{4}$ tetrahedra, the remaining unshared oxygen being linked to the phosphors by a double bond. The addition of $\mathrm{Bi}_{2} \mathrm{O}_{3}$ to this vitreous structure will transform some of $\mathrm{P}=\mathrm{O}$ bonds into crosslinking. (bridging) bonds of the type $\mathrm{P}-\mathrm{O}-\mathrm{Bi}$ and $\mathrm{P}-\mathrm{O}-\mathrm{P}$. 
Upon a further increase in $\mathrm{Bi}_{2} \mathrm{O}_{3}$ concentration the $\mathrm{Bi}$ ions may enter the glass network interstitially as network modifiers which would result in the break down of some bridging bonds in the network [6].

A suitable parameter for characterizing the overall structure of these phosphate glasses is $Q$, the average number of nonbridging oxygens per $\mathrm{PO}_{4}$ tetrahedron. The value of $Q$ can be computed directly from the composition of the glass [7-9] and is given by

$$
Q=\frac{3[\mathrm{Bi}]+3[\mathrm{Fe}]+[\mathrm{H}]}{[\mathrm{P}]}+1,
$$

where $[\mathrm{P}],[\mathrm{Bi}],[\mathrm{Fe}]$, and $[\mathrm{H}]$ are the molar concentrations of each element in the glass. In this study, there is no hydrogen in the glasses and its value has been neglected in the calculations (Eq. (1)). For phosphate glasses, there is always at least one nonbridging oxygen, even for pure $\mathrm{P}_{2} \mathrm{O}_{5}$ glass, and hence 1 must be added to the metal-to-phosphorus ratio (Eq. (1)). Since $Q$ is defined as the average number of nonbridging oxygens per $\mathrm{PO}_{4}$ tetrahedron the number of bridging oxygens per $\mathrm{PO}_{4}$ tetrahedron is simply $4-Q$. In the present work, DSC measurements are used to study the structural relaxation dynamics of a series of bismuth and bismuth-iron-phosphate glasses in which the $Q$ of the phosphate network is changed.

\section{Experimental work}

Bismuth and bismuth-iron-phosphate glasses were prepared from laboratory reagent on analar $\mathrm{P}_{2} \mathrm{O}_{5}, \mathrm{Bi}_{2} \mathrm{O}_{3}$ and $\mathrm{Fe}_{2} \mathrm{O}_{3}$ using aluminum crucibles (of $100 \mathrm{~cm}^{3}$ capacity) heated in an electric furnace open to the atmosphere. The reagents were mixed and heated at $850-1000^{\circ} \mathrm{C}$. The molten glasses were poured into a preheated boron nitride mold and annealed at the proper temperature.

The scanning calorimetry measurements were made with a Perkin-Elmer DSC-4 using crimped aluminum sample pans and a dry nitrogen atmosphere. A glass was first heated to a temperature between 50 and $100 \mathrm{~K}$ above the glass transition where the glass was in both structural and thermal equilibria. The sample was cooled through $T_{\mathrm{g}}$ to room temperature at a constant cooling rate of between 0.1 and $20 \mathrm{~K} / \mathrm{min}$. The glass was then reheated at a constant rate of $10 \mathrm{~K} / \mathrm{min}$ through the glass transition region and the heat flow into or out of the sample was recorded.

\section{Results and discussion}

Using the procedure in Refs. $[10,11]$, the normalized heat capacity data, $C_{\mathrm{n}}$, were determined. The heat capacity data at a temperature around the glass 'transition region are independent of time and are approximated by a linear function of $T$ as shown in Fig. 1. Well below $T_{\mathrm{g}}$, a heat capacity for the glass phase can be defined as: $C_{\mathrm{pg}}=A_{\mathrm{g}}+B_{\mathrm{g}} T$, where $A_{\mathrm{g}}$ and $B_{\mathrm{g}}$ are constants determined by a least-squares fit of the data. Similarly, well above $T_{\mathrm{g}}$, a heat capacity for the liquid phase can be defined as: $C_{\mathrm{p} \ell}=A_{\ell}+B_{\ell} T$. Moynihan et al. [10] showed that a natural self-consistent definition of the fictive temperature $T_{\mathrm{f}}$ is

$$
\int_{T_{\mathrm{f}}}^{T^{*}}\left(C_{\mathrm{p} \ell}-C_{\mathrm{pg}}\right) \mathrm{d} T^{\prime}=\int_{T}^{T^{*}}\left(C_{\mathrm{p}}-C_{\mathrm{pg}}\right) \mathrm{d} T^{\prime}
$$


where $C_{\mathrm{p}}$ is the measured heat capacity of the glass and $T^{*}$ is a temperature well below the $T_{\mathrm{g}}$, where the material is in both thermal and structural equilibria. Then the normalized heat capacity $C_{\mathrm{n}}$ is given by

$$
C_{\mathrm{n}}=\frac{\mathrm{d} T_{\mathrm{f}}}{\mathrm{d} T}
$$

The fictive temperature, $T_{\mathrm{f}}$, is equal to the thermodynamic temperature, $T$, when the glass has completely relaxed. Far below the glass transition region, the structure is essentially frozen and hence $\mathrm{d} T_{\mathrm{f}} / \mathrm{d} T=0$, while well above the glass transition $T_{\mathrm{f}}=T$. The normalized heat capacity, $C_{\mathrm{n}}$, varies from 0 at temperatures well below $T_{\mathrm{g}}$ to 1 at temperatures well above $T_{\mathrm{g}}$.
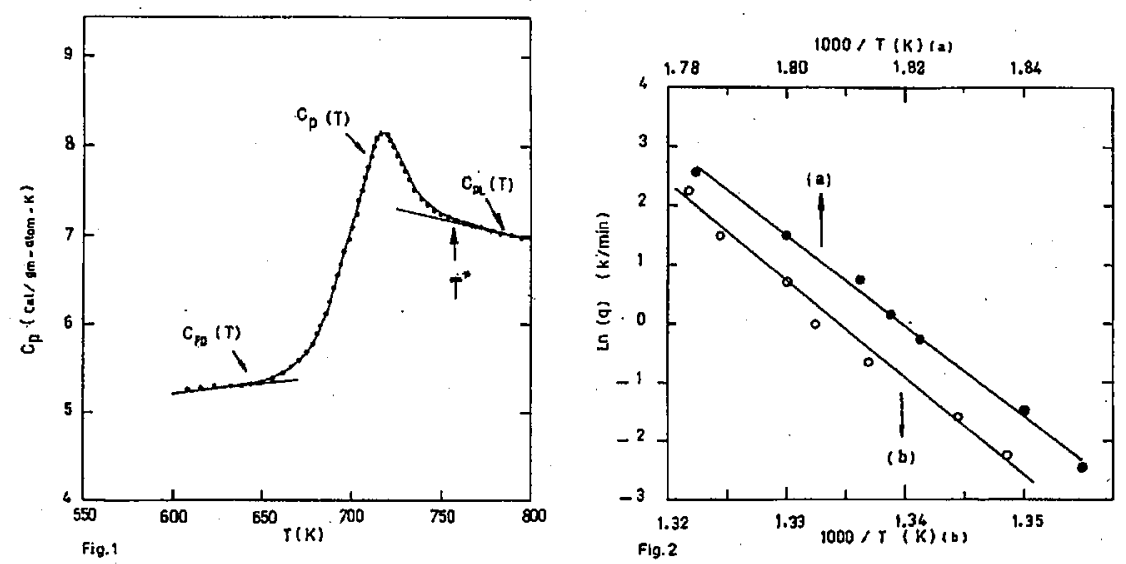

Fig. 1. Heat capacity data for $\left(0.25 \mathrm{Bi}_{2} \mathrm{O}_{3}+0.60 \mathrm{P}_{2} \mathrm{O}_{5}+0.15 \mathrm{Fe}_{2} \mathrm{O}_{3}\right)$ glass system. Fig. 2. Logarithm of the cooling rate $q[\mathrm{~K} / \mathrm{min}]$ versus the inverse of the limiting fictive temperature for (a) $\left(0.4 \mathrm{Bi}_{2} \mathrm{O}_{3}+0.6 \mathrm{P}_{2} \mathrm{O}_{5}\right)$ and (b) $\left(0.15 \mathrm{Bi}_{2} \mathrm{O}_{3}+0.6 \mathrm{P}_{2} \mathrm{O}_{5}+0.25 \mathrm{Fe}_{2} \mathrm{O}_{3}\right)$ glass systems.

The activation energy for structural relaxation, $\Delta H$, was calculated for the present glass from the plot of the cooling rate $q$ versus the limiting fictive temperature $T_{\mathrm{f}}$ as described in Ref. [10]. And $T_{\mathrm{f}}$ was obtained from Eq. (2) by choosing $T$ to be well below $T_{\mathrm{g}}$. Plots of the logarithm of the cooling rate $q$ versus the inverse of the glass transition temperature are shown in Fig. 2 for two of the glass compositions studied. The activation energy for structural relaxation, $\Delta H$, varies from $44 \mathrm{~K} \mathrm{cal} / \mathrm{mol}$ for pure $\mathrm{P}_{2} \mathrm{O}_{5}$ glass [12] to $350 \mathrm{~K} \mathrm{cal} / \mathrm{mol}$ for an iron-rich bismuth-iron-phosphate glass. The variation of $\Delta H$ with the topology of the glass is illustrated in Fig. 3, where $\Delta H$ is plotted versus the average number of nonbridging oxygens per $\mathrm{PO}_{4}$ tetrahedron $(Q)$. From Fig. 3. we can see that $\Delta H$ increases systematically with increasing $Q$. There may be, however, a slight decrease in $\Delta H$ as iron is initially added to the bismuth phosphate glasses.

The DSC data for the present glass can be fitted to the Adam-Gibbs-Sherer (AGS) model. The continuous heating or cooling at a constant rate can be thought as a series of differential temperature jumps $\mathrm{d} T$ followed by isothermal holds which 


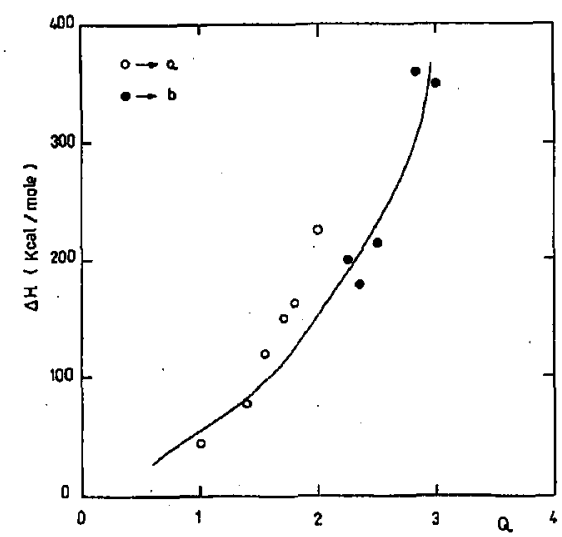

Fig. 3. Variation of the apparent activation energy for structural relaxation $\Delta H$ with $Q$ for (a) bismuth-phosphate and (b) bismuth-iron-phosphate glasses.

last for a time, $\mathrm{d} t=\mathrm{d} T / q$, where $q$ is the rate of heating or cooling $[10,11]$. If a glass, initially in both structural and thermal equilibria at a temperature $T_{0}$, is subjected to a series of small temperature jumps $\mathrm{d} T_{i}$ at a time $t_{i}$, the response of the glass structure can be expressed as a superposition of the responses to the various temperature changes at their respective times

$$
\begin{aligned}
T_{\mathrm{f}}= & T_{0}+\left[1-\phi\left(t-t_{1}, t\right)\right] \mathrm{d} T_{1}+\left[1-\phi\left(t-t_{2}, t\right)\right] \mathrm{d} T_{2} \\
& +\ldots\left[1-\phi\left(t-t_{n}, t\right)\right] \mathrm{d} T_{n} .
\end{aligned}
$$

The degree to which the glass structure has relaxed is expressed in terms of the fictive temperature, $T_{\mathrm{f}}(t)$. The relaxation function $\phi(t)$ is a function of both temperature and time and is equal to 1 for $t=0$ and 0 for $t=\infty$.

The dynamics of the glass transition is included in the particular form that is assumed for $\phi(t, T)$. For infinitesimal temperature jumps, a convenient expression for the time dependence of $\phi(t)$ is the stretched exponential [13-15]

$$
\phi(t)=\exp (t / \tau)^{\beta},
$$

where $0<\beta<1$ and is assumed to be independent of temperature. This form of $\phi(t)$ can be thought as corresponding to a distribution of relaxation paths each with a different relaxation time. For values of $\beta$ near 1 , the distribution of relaxation times is narrow, while for values of $\beta$ near 0 the distribution of relaxation times is broad. Many workers [16-18] have used a purely phenomenological equation for $\tau\left(T, T_{\mathrm{f}}\right)$. Although the use of this equation gave excellent fits to the data, some of the model parameters were without any clear physical significance.

Recently Scherer [5] suggested another form for $\tau\left(T, T_{\mathbf{f}}\right)$ based on AdamGibbs equation [4]

$$
\tau=A \exp \left(\frac{\Delta \mu S_{\mathrm{c}}^{*}}{K T S_{\mathrm{c}}}\right)
$$

where $\Delta \mu$ is the free-energy barrier hindering rearrangement of a small segment of the glass network, $S_{\mathrm{c}}^{*}$ is the configurational entropy of the smallest part of the 
network capable of rearranging $\left[S_{\mathrm{c}}^{*} \approx \ln (2)\right]$, and $S_{\mathrm{c}}$ is the macroscopic configurational entropy. In the region of the glass transition, the configurational entropy is given by

$$
S_{\mathrm{c}}=\int_{T_{2}}^{T_{1}}(\Delta C / T) \mathrm{d} T,
$$

where $T_{2}$ is the Kauzmann temperature and $\Delta C$ is equal to the configurational contribution to the heat capacity in the region of the glass transition. A better approximation was suggested by Hodge [19], he reported that, if one takes $\Delta C=C_{0} / T$, then in the high temperature limit (where $T_{\mathrm{f}}=T$ ) the expression for $\tau$ reduces to the Fulcher equation which fits the viscosity data for many glasses [20]. In order to check whether this approximation is valid for the present phosphate glass data, it is noted that $C_{0} / T$ can be expanded as

$$
\frac{C_{0}}{T}=2 \frac{C_{0}}{T_{0}}-\frac{C_{0} T}{T_{0}^{2}},
$$

where $T_{0}$ is a temperature in the middle of the glass transition range. This approximation for $\Delta C$ can then be compared with the experimental finding that

$$
\Delta C=\left(A_{\ell}-A_{\mathrm{g}}\right)+\left(B_{\ell}-B_{\mathrm{g}}\right) T .
$$

For $C_{0} / T$ to be a reasonable approximation to $\Delta C$ in the vicinity of the glass transition, it requires that

$$
\frac{\left(B_{\ell}-B_{\mathrm{g}}\right)}{\left(A_{\ell}-A_{\mathrm{g}}\right)} \approx-\frac{1}{2 T_{0}} \approx-10^{-3}\left[\mathrm{~K}^{-1}\right] .
$$

As can be observed in Table I which shows the experimental values of $\left(A_{\ell}-A_{g}\right)$ and $\left(B_{\ell}-B_{\mathrm{g}}\right) /\left(A_{\ell}-A_{\mathrm{g}}\right)$, this was indeed found to be the case.

Using the approximation of $\Delta C=C_{0} / T$, the relaxation time is given by

$$
\tau=A \exp \left[\frac{D}{T\left(1-T_{2} / T_{\mathrm{f}}\right)}\right]
$$

where $D=\Delta \mu S_{\mathrm{c}}^{*} T_{2} / C_{0} R$. Experimentally, $C_{0}$ is approximately given by $T_{\mathrm{g}} \Delta C\left(T_{\mathrm{g}}\right)$.

The values of $A, D, T_{2}$ and $\beta$ were determined for the present glass compositions by using Eqs. (4), (5) and (8) and a nonlinear fitting procedure as described by Bevington [21].

Figures $4 \mathrm{a}-\mathrm{f}$ show typical examples of the best fits of the normalized heat capacity data to the Adam-Gibbs-Scherer model for the present glass systems. The best values of the fitting parameters for all of the present glass systems studied are given in Table II.

The calorimetry data taken by Martin and Angell on pure $\mathrm{P}_{2} \mathrm{O}_{5}$ [12] were also analyzed using the same model for structural relaxation. The approximate best fit to the $\mathrm{P}_{2} \mathrm{O}_{5}$ calorimetry data is shown in Fig. 5 .

The apparent activation energy for structural relaxation, $\Delta H$, implicitly assumes that above $T_{\mathrm{g}}$ the relaxation time, $\tau$, will be proportional to $\exp (\Delta H / K T)$ [10]. As has been noted by Refs. $[19,22]$, one can relate $\Delta H$ to the parameters of the AGS model. At temperatures slightly above $T_{\mathrm{g}}, T_{\mathrm{f}}=T$ and we can equate the temperature coefficient of $\tau$ as given by Eq. (8) with $\Delta H$. This requirement 
TABLE I

Experimental values for the jump in the heat capacity near the glass transition for $\left[x \mathrm{Bi}_{2} \mathrm{O}_{3}+(1-x) \mathrm{P}_{2} \mathrm{O}_{5}\right]$ and $\left[x \mathrm{Bi}_{2} \mathrm{O}_{3}+(1-x-y) \mathrm{P}_{2} \mathrm{O}_{5}+\right.$ $y \mathrm{Fe}_{2} \mathrm{O}_{3}$ ] glass systems.

\begin{tabular}{c|c|c|c}
\hline \hline $\begin{array}{c}\text { Composition } \\
\text { mole\% }\end{array}$ & $\begin{array}{c}\Delta C\left(T_{\mathrm{g}}\right) \\
\text { [cal mole K] }\end{array}$ & $\begin{array}{c}\left(A_{\ell}-A_{\mathrm{g}}\right) \\
{[\mathrm{cal} / \mathrm{mole} \mathrm{K}]}\end{array}$ & $\begin{array}{c}\left(B_{\ell}-B_{\mathrm{g}}\right) /\left(A_{\ell}-A_{\mathrm{g}}\right) \\
{\left[10^{-3} \mathrm{~K}^{-1}\right]}\end{array}$ \\
\hline$x=0.00[11]$ & 1.5 & $3+1$ & $-0.8+0.2$ \\
$=0.15$ & 1.7 & $4+1$ & $-1.3+0.1$ \\
$=0.30$ & 2.2 & $6+1$ & $-1.4+0.1$ \\
$=0.40$ & 1.8 & $6.5+1$ & $-1.3+0.1$ \\
$=0.60$ & 2.1 & $9+1$ & $-1.3+0.1$ \\
$y=0.00$ & 1.8 & $6.5+1$ & $-1.3+0.1$ \\
$=0.05$ & 1.7 & $5+1$ & $-0.9+0.1$ \\
$=0.10$ & 1.8 & $2+1$ & $-0.6+0.1$ \\
$=0.15$ & 1.9 & $4+1$ & $-1.0+0.1$ \\
$=0.20$ & 2.8 & $7.5+1$ & $-0.8+0.1$ \\
$=0.25$ & 3.1 & $8.5+1$ & $-0.7+0.1$
\end{tabular}

TABLE II

The AGS fitting parameters and $T_{\mathrm{g}}$ of the calorimetry data for the $\left[x \mathrm{Bi}_{2} \mathrm{O}_{3}+(1-x) \mathrm{P}_{2} \mathrm{O}_{5}\right]$ and $\left[x \mathrm{Bi}_{2} \mathrm{O}_{3}+(1-x-y) \mathrm{P}_{2} \mathrm{O}_{5}+\right.$ $y \mathrm{Fe}_{2} \mathrm{O}_{3}$ ] glass systems.

\begin{tabular}{c|c|c|c|c|c|c}
\hline \hline $\begin{array}{c}\text { Composition } \\
\text { mole\% }\end{array}$ & $\begin{array}{c}D \\
{[\mathrm{~K}]}\end{array}$ & $\begin{array}{c}D^{\prime} \\
{[\mathrm{K}]}\end{array}$ & $\ln (A)$ & $B$ & $\begin{array}{c}T_{2} \\
{[\mathrm{~K}]}\end{array}$ & $\begin{array}{c}T_{\mathrm{g}} \\
{[\mathrm{K}]}\end{array}$ \\
\hline$x=0.00[11]$ & 13014 & 51035 & -23.69 & 0.77 & 150 & 588 \\
$=0.15$ & 14901 & 37301 & -49.89 & 0.61 & 160 & 420 \\
$=0.30$ & 15890 & 35122 & -58.99 & 0.48 & 170 & 420 \\
$=0.40$ & 14611 & 26871 & -49.82 & 0.61 & 290 & 530 \\
$=0.60$ & 15132 & 28123 & -50.25 & 0.67 & 300 & 550 \\
$y=0.00$ & 14611 & 26871 & -49.82 & 0.61 & 290 & 530 \\
$=0.05$ & 15185 & 30413 & -57.31 & 0.63 & 285 & 610 \\
$=0.10$ & 16001 & 33871 & -53.21 & 0.67 & 270 & 611 \\
$=0.15$ & 22031 & 38592 & -58.63 & 0.63 & 289 & 681 \\
$=0.20$ & 23261 & 35981 & -65.11 & 0.58 & 360 & 720 \\
$=0.25$ & 25215 & 36219 & -67.92 & 0.60 & 390 & 753
\end{tabular}



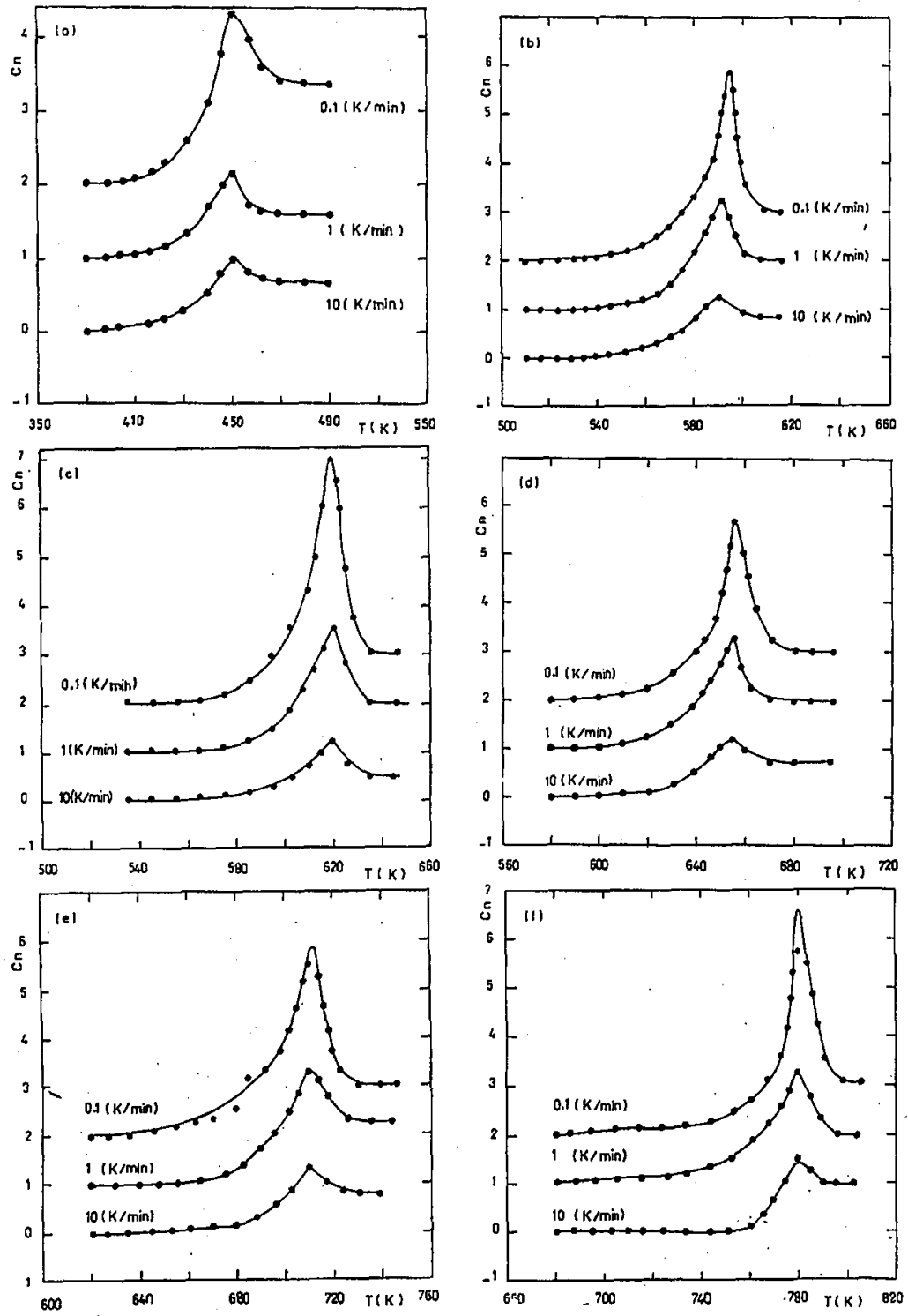

Fig. 4. Correlation between the normalized heat capacity data (data points) and the best fit calculated using the AGS model (solid curves) for (a) $\left(0.3 \mathrm{Bi}_{2} \mathrm{O}_{3}+0.7 \mathrm{P}_{2} \mathrm{O}_{5}\right)$, (b) $\left(0.4 \mathrm{Bi}_{2} \mathrm{O}_{3}+0.6 \mathrm{P}_{2} \mathrm{O}_{5}\right)$, (c) $\left(0.6 \mathrm{Bi}_{2} \mathrm{O}_{3}+0.4 \mathrm{P}_{2} \mathrm{O}_{5}\right)$, (d) $\left(0.35 \mathrm{Bi}_{2} \mathrm{O}_{3}+0.6 \mathrm{P}_{2} \mathrm{O}_{5}+\right.$ $\left.0.05 \mathrm{Fe}_{2} \mathrm{O}_{3}\right)$, (e) $\left(0.25 \mathrm{Bi}_{2} \mathrm{O}_{3}+0.6 \mathrm{P}_{2} \mathrm{O}_{5}+0.15 \mathrm{Fe}_{2} \mathrm{O}_{3}\right)$, (f) $\left(0.15 \mathrm{Bi}_{2} \mathrm{O}_{3}+0.6 \mathrm{P}_{2} \mathrm{O}_{5}+\right.$ $0.25 \mathrm{Fe}_{2} \mathrm{O}_{3}$ ) glass systems at a cooling rates of $0.1,1$ and $10 \mathrm{~K} / \mathrm{min}$. 


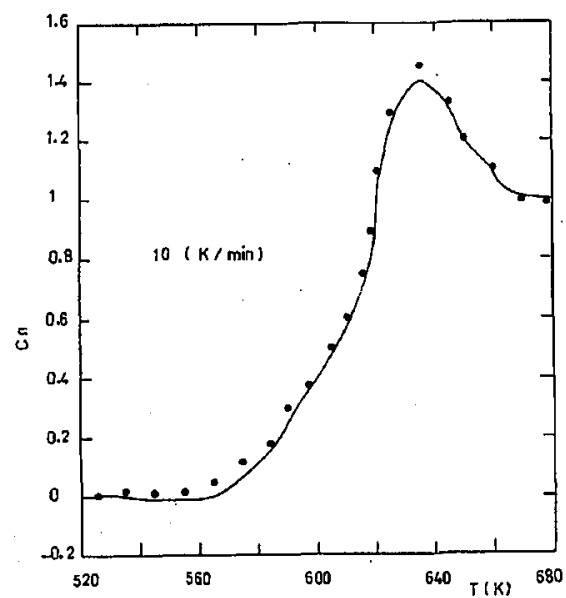

Fig. 5. Correlation between the normalized heat capacity data (data points) from Ref. [11] and the best fit calculated using the AGS model (solid curves) for a pure $\mathrm{P}_{2} \mathrm{O}_{5}$ glass at a cooling rate of $10 \mathrm{~K} / \mathrm{min}$.

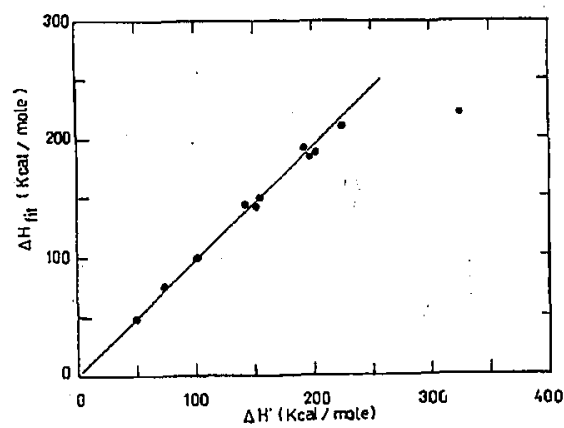

Fig. 6. Correlation between the apparent activation energies $\Delta H$ and $\Delta H_{\text {fit }}$ (as calculated from Eq. (9)).

implies that $R \mathrm{~d} \ln \tau / \mathrm{d}(1 / T)=\Delta H$ for temperatures near $T_{\mathrm{g}}$. The relationship between $\Delta H$ and the ASG parameters is

$$
\Delta H \approx \frac{R D}{\left(1-T_{2} / T_{\mathrm{g}}\right)^{2}}
$$

The above equation is only valid for temperatures near $T_{\mathrm{g}}$, and this result depends on the fact that any temperature-dependent rate can be fitted to the Arrhenius law if the temperature interval is sufficiently narrow. It can be seen from Fig. 6 that there is a linear correlation between the apparent activation energies $\Delta H$ (determined as in Fig. 2) and $\Delta H_{\text {fit }}$ (calculated from Eq. (9)).

The qualitative concept of a strong or fragile glass was introduced by Angell [23] to describe the stability of intermediate range order in the liquid region 
above $T_{\mathrm{g}}$ against a temperature increase. Strong glasses have tetrahedral networks, which tend to resist the breakup of the intermediate range order. These glasses typically exhibit a rather slow decrease in the shear viscosity with increasing temperature. However, fragile glasses usually have a large number of ionic or metallic bonds that produce a high degree of configurational degeneracy. With increasing temperature, the intermediate range order is rapidly destroyed and the shear viscosity decreases rapidly. By plotting the log of the viscosity or relaxation time above $T_{\mathrm{g}}$ versus $T_{\mathrm{g}} / T$, we can distinguish strong network glasses from fragile ionic glasses. The viscosity data from the strong glasses are often well approximated by the Arrhenius temperature dependence and, hence these data fall on a straight line with a good slope when plotted versus $T_{\mathrm{g}} / T$. The viscosity data from the fragile glasses are better approximated by the Fulcher equation (Eq. (8)) which, on a normalized viscosity plot, decreases rapidly for temperatures just above $T_{\mathrm{g}}$ and exhibits substantial negative curvature at higher temperatures.

At temperatures above the glass transition, the behavior of the viscosity (which is proportional to the relaxation time) of the bismuth and bismuth-ironphosphate glasses can be deduced using Eq. (8) and the best fit parameters for $D$ and $T_{2}$ given in Table II on condition that above $T_{\mathrm{g}}, T_{\mathrm{f}}=T$.

The author wishes to thank very much Prof. Cerdera and his group in Campinas University Brazil for the experimental facilities and very useful discussions during this work.

\section{References}

[1] W. Kauzmann, Chem. Rev. 43, 219 (1948).

[2] C. Angell, W. Sichnia, Annu. Rep. NY Acad. Sci. 53, 279 (1976).

[3] C. Angell, K. Rao, J. Chem. Phys. 57, 470 (1972).

[4] G. Adam, J. Gibbs, J. Chem. Phys. 43, 139 (1965).

[5] G. Scherer, J. Am. Ceram. Soc. 67, 504 (1984).

[6] A. El-Adawy, Ph.D. Thesis, Menuofia University (Egypt) 1992.

[7] D. Jacobs, M. Thorpe, Phys. Rev. Lett. 75, 4051 (1995).

[8] M. Thorpe, J. Non-Cryst. Solids 182, 135 (1995).

[9] Y. Cai, M. Thorpe, Phys. Rev. B 40, 10535 (1989).

[10] C. Moynihan, A. Eastal, M. Debolt, J. Tucker, J. Am. Ceram. Soc. 59, 12 (1976).

[11] M. Debolt, A. Eastal, P. Macedo, C. Moynihan, J. Am. Ceram. Soc. 59, 16 (1976).

[12] S. Martin, C. Angell, J. Phys. Chem. 90, 6736 (1986).

[13] C. Moynihan, L. Boesch, N. Laberge, Phys. Chem. Glass. 14, 122 (1973).

[14] G. Williams, D. Watts, J. Chem. Soc. Faraday Trans. 66, 80 (1970).

[15] J. Klafter, M. Shlesinger, in: Fractal Aspects of Materials, Materials Research Society, Pittsburgh 1985, p. 13.

[16] O. Narayanaswamy, J. Am. Ceram. Soc. 54, 491 (1971).

[17] I. Hodge, Macromol. 16, 898 (1983).

[18] A. Eastal, J. Wilder, R. Mohr, C. Moynihan, J. Am. Ceram. Soc. 60, 143 (1977).

[19] I. Hodge, Macromol. 19, 936 (1986). 
[20] G. Fulcher, J. Am. Ceram. Soc. 8, 936 (1925).

[21] P. Bevington, Data Reduction and Error Analysis for the Physical Sciences, McGraw-Hill, New York 1969.

[22] I. Hodge, Macromol. 20, 2897 (1987).

[23] C. Angell, J. Non-Cryst. Solids 102, 205 (1988). 